
AFMRD Fom the essodidion Residency Directors Residency Directors

Ann Fam Med 2019;17:90. https://doi.org/10.1370/afm.2349.

\section{SURVIVING THE SOAP}

The end of February usually brings a great deal of relief for residency programs. We have successfully weathered another recruiting season. Hundreds of qualified applications were reviewed, and hours of interviews were completed. The anxious phone calls and solicitous e-mails taper off. We are left amazed by the quality of students applying for post-graduate training and we begin to rank those who we feel would be the best fit for our program. The excitement of match day approaches with all of the pomp and traditions. On occasion, however, the excitement and anticipation is unexpectedly disrupted: an e-mail arrives stating your program did not fill all of its positions.

This past year, we found our programs in this position. It took mere seconds for the numbness to convert to mania and borderline terror, as we began to make lists of all that needed to unfold. After all, we had only 48 hours to fill available positions in the Supplemental Offer and Acceptance Program (SOAP).

Meanwhile, a flurry of panic was brewing among medical schools as they coordinated to support unmatched students. Some applicants had prepared for the possibility of "SOAPing" - they worked with advisers to refine their personal statement ahead of time. Others were completely blindsided, shrouded in tears as the calls started coming in from interested programs. As we scrambled our resources to review and interview applicants there were hundreds of potential family doctors out there waiting for a call or e-mail.

The SOAP systematically places unmatched applicants into open residency positions, previously accomplished with the "Scramble." For those programs that find themselves in this position, there are several pearls to consider.

The Program Director should have an open schedule and marshal available faculty, residents, and administrators to provide focused and objective evaluations of applications. Considerable time is required to screen and interview the applicants you feel would be a good fit for the program. Choosing a systematic evaluation of available candidates makes things more manageable as you scour the applications. Some students may have poor test scores with amazing clinical reviews. Others may have anomalous failures that are easily balanced by their leadership experiences. Students who planned to train in a different specialty may now be reaching out to family medicine residency programs. All these students have 1 thing in common: eagerness to begin training to be a doctor. Their roots from medical school have resurfaced and their purpose is now to simply become a doctor.

The SOAP process forces programs to approach their pile of applications much differently and can lead to changes in the overall recruitment process. For example, programs may find new opportunities to review applicants more holistically to find the best match for both the program and the student.

Going through the SOAP does not have to be a negative experience. In fact, the residents we obtained through the SOAP were eager, well-qualified physicians who, for some reason or another, had not considered our program previously. The SOAP brought together available residency training positions with well-prepared, bright future family physicians.

The AFMRD has started to build a toolbox of resources for programs that find themselves entering the SOAP for the first time. Guidance on the timeline, the "dos and don'ts," and the structures to consider for interviewing are provided by fellow Program Directors who have successfully found residents through the SOAP. Hopefully, these resources will help programs approach the SOAP without fear and devastation. Curtis L. Galke, DO, FAAFP and Katie Hartl, MD

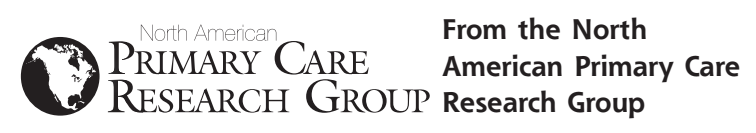

Ann Fam Med 2019;17:90-91. https://doi.org/10.1370/afm.2350.

\section{NORTH AMERICAN PRIMARY CARE RESEARCH GROUP POSITION STATEMENT ON ELECTRONIC HEALTH RECORD INFORMATION BLOCKING}

Information exchange is critical to ensuring that patients receive the right care, at the right place, and at the right time. Increasingly, this communication depends on the secure, effective, and efficient delivery of information elctronically. ${ }^{1}$ To ensure health information technology (HIT) investments ultimately lead to greater value, the Health Information Technology for Clinical and Economic Health (HITECH) Act included provisions to develop the infrastructure for health information exchange (HIE). ${ }^{2}$ In response, health care providers have increasingly adopted 
and, thus, stored health data in electronic health records (EHRs). ${ }^{3}$

For many reasons, effective HIE has failed to materialize. In part, EHR vendors and health systems have engaged in information blocking in order to increase revenue and market share. The Office of the National Coordinator, which leads and coordinates US HIT efforts, reports that information blocking "occurs when persons or entities knowingly and unreasonably interfere with the exchange or use of electronic health information." ${ }^{\prime 1}$ While more research is needed to quantify the impact of these practices, one-half of national HIE leaders that responded to a survey reported that EHR vendors routinely block the flow of information. The most common practices include deploying products with limited interoperability, charging disproportionately high fees for HIE, and making third party access to standardized data difficult. ${ }^{2}$

These practices have implications for quality improvement, research, and patient care. Providers and scholars increasingly rely on EHR data to track diseases, study interventions, and refine the delivery of care. These activities are critical as health systems embrace learning health care principles. ${ }^{4}$ Within primary care, organizations are aggregating demographic, social determinants of health, clinical, and billing data extracted from EHRs to coordinate care, conduct comparative effectiveness research, and accelerate learning across practices. ${ }^{5-7}$

Recognizing the importance of these data for the future of primary care research, the North American Primary Care Research Group's (NAPCRG) Research Advocacy Committee drafted and Board passed a position statement condemning information blocking. ${ }^{8}$ This statement will guide advocacy efforts and policies and aligns with similar calls from the College of Family Physicians Canada and American Academy of Family Physicians. ${ }^{9}$ As we seek to understand the scope of the problem and potential solutions, we welcome your feedback about this statement, your experiences with information blocking, and your ideas about how NAPCRG can support effective HIE (see the link for an online form). ${ }^{8}$

Winston Liaw, MD, MPH, ${ }^{1}$ University of Houston, College of Medicine, Department of Health Systems and Population Healtb Sciences; Sabrina Wong, RN, PbD, University of British Columbia, School of Nursing and Centre for Health Services and Policy Research

\section{References}

1. Office of the National Coordinator for Health Information Technology (ONC). Department of Health and Human Services. Report to Congress. Report on Health Information Blocking. April 2015:39.

2. Adler-Milstein J, Pfeifer E. Information blocking: is it occurring and what policy strategies can address it? Milbank Q. 2017;95(1):117-135.
3. Office of the National Coordinator for Health Information Technology. Office-based Physician Health IT Adoption and Use. https:// dashboard.healthit.gov/datadashboard/documentation/physicianhealth-it-adoption-use-data-documentation.php. Accessed Feb 26, 2018.

4. Smith MD. Institute of Medicine (US), eds. Best Care at Lower Cost: The Path to Continuously Learning Health Care in America. Washington, DC: National Academies Press; 2012.

5. DeVoe JE, Gold R, Cottrell E, et al. The ADVANCE network: accelerating data value across a national community health center network. J Am Med Inform Assoc. 2014;21(4):591-595.

6. Garies S, Birtwhistle R, Drummond N, Queenan J, Williamson T. Data Resource Profile: national electronic medical record data from the Canadian Primary Care Sentinel Surveillance Network (CPCSSN). Int J Epidemiol. 2017;46(4):1091-1092f.

7. Pace WD, Cifuentes M, Valuck RJ, Staton EW, Brandt EC, West DR. An electronic practice-based network for observational comparative effectiveness research. Ann Intern Med. 2009;151(5):338-340.

8. North American Primary Care Research Group. Research Advocacy Committee. http://www.napcrg.org/AboutUs/Committees/ ResearchAdvocacy.

9. American Academy of Family Physicians. AAFP, other groups demand Health and Human Services stop stalling on regulations. https://www.aafp.org/news/governmentmedicine/20180809hhsblocking.html. Published Aug 9, 2018.

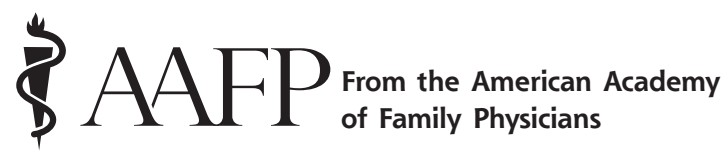

Ann Fam Med 2019;17:91-92. https://doi.org/10.1370/afm.2345.

\section{CULLEN: FAMILY PHYSICIANS ARE HEROES IN 'EPIC ADVENTURE' OF US HEALTH CARE}

John Cullen, MD, the AAFP's newly installed president, barely had time to catch his breath after his formal swearing-in on October 10, 2018 before he was thrust into the limelight at the opening ceremony of the AAFP's 2018 Family Medicine Experience (FMX) in New Orleans.

As he stood before a standing-room-only crowd of his family physician colleagues and other well-wishers, Cullen introduced himself and spoke of the joy and challenges of family medicine. "My practice in Alaska has been an adventure, but it has not been easy," said Cullen. The Valdez Medical Clinic where Cullen has seen patients for some 25 years is more than 300 miles from any other hospital. "The weather is something that must be experienced to be believed," he said. "Family medicine is the only specialty that can thrive where we live," Cullen told his audience.

He spoke of storms - a driving snowstorm in Valdez and a young mother in labor with twins at 34 weeks. "The first baby was breech," he said, and the family physicians in the audience gasped. "And there 